\title{
ACTA PHYSIOLOGICA
}

\section{Characterization of cold-induced remodeling reveals depot- specific differences across and within brown and white adipose tissues in mice}

\begin{tabular}{|c|c|}
\hline Journal: & Acta Physiologica \\
\hline Manuscript ID & APH-2015-09-0357.R2 \\
\hline Manuscript Type: & Regular Paper \\
\hline Date Submitted by the Author: & $\mathrm{n} / \mathrm{a}$ \\
\hline Complete List of Authors: & $\begin{array}{l}\text { jia, ru; Xi'an Jiaotong University, Prosthodontics } \\
\text { Luo, Xiao-qin; School of Public Health, Xi'an Jiaotong University Health } \\
\text { Science Center, Department of Medicine } \\
\text { Wang, Guan; Department of Biology, Boston University } \\
\text { Lin, Cai-xia; Xi'an Jiaotong University Health Science Center, Department } \\
\text { of Physiology and Pathophysiology } \\
\text { Qiao, Hu; Xi'an Jiaotong University, Prosthodontics } \\
\text { Wang, Nan; Xi'an Jiaotong University Health Science Center, Department } \\
\text { of Physiology and Pathophysiology } \\
\text { Yao, Ting; Xi'an Jiaotong University Health Science Center, Department of } \\
\text { Physiology and Pathophysiology } \\
\text { Barclay, Johanna; Translational Research Institute, Metabolic } \\
\text { Program,Mater research Institute-University of Queensland } \\
\text { Whitehead, Jonathan; Translational Research Institute, Metabolic } \\
\text { Program,Mater research Institute-University of Queensland } \\
\text { Luo, Xiao; Xi'an Jiaotong University Health Science Center, Physiology and } \\
\text { Pathophysiology } \\
\text { yan, jianqun; Xi'an Jiaotong University, Physiology and Pathophysiology }\end{array}$ \\
\hline Key Words: & beige cells, brown adipose tissue, cold exposure, time course, UCP-1 \\
\hline
\end{tabular}

\section{SCHOLARONE ${ }^{m}$}




\title{
Characterization of cold-induced remodeling reveals depot-specific differences across and within brown and white adipose tissues in mice
}

Running title: Cold-induced remodelling of BAT and WAT

\author{
Ru Jia ${ }^{1,2,3}$,Xiao-qin Luo ${ }^{4}$, Guan Wang ${ }^{5}$, Cai-xia Lin ${ }^{1,2}$, Hu Qiao ${ }^{1,2}$, Nan Wang ${ }^{1,2}$, \\ Ting Yao ${ }^{1,2}$, Johanna L. Barclay ${ }^{6,7}$, Jonathan P. Whitehead ${ }^{6,7}$, Xiao Luo ${ }^{1,2, a}$ and \\ Jian-qun Yan ${ }^{1,2, a}$ \\ ${ }^{1}$ Department of Physiology and Pathophysiology, School of Basic Medical Sciences, \\ Xi'an Jiaotong University Health Science Center, Xi' an 710061, PR China \\ ${ }^{2}$ Key Laboratory of Environment and Genes Related to Diseases (Xi'an Jiaotong \\ University), Ministry of Education of China, PR China \\ ${ }^{3}$ Department of Prosthodontics, Stomatological Hospital, College of Stomatology, Xi' \\ an Jiaotong University, Xi'an, 710061, PR China \\ ${ }^{4}$ Department of Medicine, School of Public Health, Xi'an Jiaotong University Health \\ Science Center, Xi'an 710061, PR China \\ ${ }^{5}$ Department of Biology, Boston University, Boston, MA 02215, USA \\ ${ }^{6}$ Mater Research Institute, University of Queensland, Brisbane, 4101, Australia \\ ${ }^{7}$ Translational Research Institute, Brisbane, 4102, Australia
}

\section{${ }^{a}$ Corresponding Authors:}

Xiao Luo

Xi'an Jiaotong University

76 Yanta Western Road

Shaanxi, 710061, P.R.China

Tel: 682982655199

Fax: 682982655199

Email:xluo@mail.xjtu.edu.cn
Jian-qun Yan

Xi'an Jiaotong University

76 Yanta Western Road

Shaanxi, 710061, P.R.China

Tel: 682982655199

Fax: 682982655199

Email: jqyan810@163.com

Word count: 4963/ Figures: 5/ Tables: 1/ Supporting data: 3 


\begin{abstract}
Brown and beige adipose tissue dissipate energy in the form of heat via mitochondrial uncoupling protein 1 , defending against hypothermia and potentially obesity. The latter has prompted renewed interest in understanding the processes involved in browning to realize potential therapeutic benefits.
\end{abstract}

Aim: To characterize the temporal profile of cold-induced changes and browning of brown and white adipose tissue in mice.

Methods: Male C57BL/6J mice were singly housed in conventional cages under cold exposure $\left(4^{\circ} \mathrm{C}\right)$ for $1,2,3,4,5$ and 7 days. Food intake and body weight were measured daily. Interscapular brown adipose tissue (iBAT), inguinal subcutaneous (sWAT) and epididymal white adipose tissues (eWAT) were harvested for histological, immunohistochemical, gene and protein expression analysis.

Results: Upon cold exposure food intake increased whilst body weight and adipocyte size were transiently reduced. iBAT mass was increased whilst sWAT and eWAT were transiently decreased. A combination of morphological, genetic (Ucp-1, Pgc-1 $\alpha$ and Elov13) and biochemical (UCP-1, PPAR $\gamma$ and aP2) analyses demonstrated depot-specific remodeling in response to cold exposure.

Conclusion: Our results demonstrate differential responses to cold-induced changes across discrete BAT and WAT depots, and support the notion that the effects of short-term cold exposure are achieved by expansion, activation and increasing thermogenic capacity of iBAT, as well as browning of sWAT and, to a lesser extent, eWAT. 
Keywords: beige cells, brown adipose tissue, cold exposure, time course, UCP-1

\section{Introduction}

Adipose tissue plays an important role in the regulation of energy homeostasis and has been shown to be a crucial factor linking obesity to its metabolic complications. Functionally and morphologically, adipose tissue can be divided into two distinct types in mammals, white adipose tissue (WAT) and brown adipose tissue (BAT). WAT is the major site of triglyceride storage and provides substrates in terms of energy needs by releasing free fatty acids and glycerol. BAT dissipates chemical energy in the form of heat, most notably when environmental temperatures fall (Gesta et al. 2007, Stephens et al. 2011). This heat-dissipating process is accomplished by uncoupling protein 1 (UCP-1), which is a mitochondrial protein that uncouples oxidative phosphorylation from ATP production for the purpose of generating heat (Cannon \& Nedergaard 2004). The activation of BAT helps to prevent genetic obesity, insulin resistance and type 2 diabetes (Cannon \& Nedergaard 2011, Vernochet et al. 2010).

It has recently become clear that there are two distinct types of BAT. Constitutive or classical BAT (cBAT) is of embryonic origin and anatomically located in the interscapular region in rodents, and has a muscle-like $\mathrm{Myf}^{+}, \mathrm{En} 1^{+}, \mathrm{Pax}^{+}$cell lineage signature (Timmons et al. 2007, Atit et al. 2006, Lepper \& Fan 2010, Seale et al. 2008). Recruitable BAT (rBAT), resides within subcutaneous white adipose tissue (sWAT), and can express high levels of UCP-1 upon prolonged stimulation by cold or 
the elevation of intracellular cyclic AMP (cAMP) (Xue et al. 2005). These adipocytes are termed beige or 'brite' (brown in white) cells, and display a Myf5 $5^{\text {neg }}$ lineage signature (Ishibashi \& Seale 2010, Petrovic et al. 2010, Seale et al. 2008, Timmons et al. 2007). However, recent discoveries demonstrated that 'brite' adipocytes might also have multiple origins, including both $\mathrm{My}^{+}$and $\mathrm{My}^{\text {neg }}$ precursors (Sanchez-Gurmaches et al. 2012, Sanchez-Gurmaches \& Guertin 2014). Similar to cBAT, beige cells in sWAT are characterized by their multilocular appearance, high mitochondrial content and the expression of a series of BAT enriched proteins, such as UCP-1, elongation of very long chain fatty acid 3 (ELOVL3), peroxisome proliferator-activated receptor- $\gamma$ coactivator $1-\alpha(\mathrm{PGC} 1-\alpha)$ and cell death-inducing DFFA-like effector a (CIDEA). In several rodent models, expanding beige cells appears to be protective against diet-induced metabolic disorders, including obesity and diabetes (Cao et al. 2011, Seale et al. 2011). Therefore, beige adipogenesis in WAT has been proposed as a potential new therapeutic approach for obesity.

Cold exposure, which induces thermogenic features in adipose tissue, is also a dominant regulator of beige adipogenesis and function. Compared to $\beta 3$-adrenergic agonists (Robidoux et al. 2004) which cause supra-physiologically elevated levels of UCP-1, cold exposure is a physiological manipulation in which the expression of genes involved in glucose uptake and catabolism are significantly elevated, increasing metabolic rate and alleviating metabolic syndrome (Yu et al. 2002). Therefore, many research groups have chosen this approach to study beige adipocyte activation and systemic adiposity. However, the models of cold stimulation employed by different 
research groups differ vastly, with some studies exposing rodents for several hours and others for several days (Nakamura et al. 2013, Schulz et al. 2013, Shore et al. 2013, Yu et al. 2015). Barbatelli et al. reported the presence of multilocular adipocytes at several time points of cold acclimation, and beige adipogenesis occurred after several days of cold exposure (Barbatelli et al. 2010). However, a more comprehensive temporal profile of physiological, morphological, genetic and biochemical events under cold stimulation has not yet been documented. Further, it is unclear whether different time periods in the cold results in different effects on BAT activation and beige adipogenesis in different adipose depots. Furthermore, contradictory effects on body weight and WAT weight have been observed, with some studies showing decreased weight gain in rodents exposed to cold, and others showing no alterations in body weight and body fat composition (Ravussin et al. 2014, Shefer \& Talan 1997, Wang et al. 2013, Yoo et al. 2014). Moreover, some studies reported that cold exposure enhances both glucose-derived lipogenesis and fatty acid oxidation in BAT, but its effects on WAT were controversial (Jakus et al. 2008, Yu et al. 2002). Therefore, it is necessary to clarify the dynamic changes of adipose tissue and body weight during cold exposure.

In this study, we have characterized basic metabolic parameters in male $\mathrm{C} 57 \mathrm{BL} / 6 \mathrm{~J}$ mice in response to a time course of cold exposure (up to 7 days). We have also determined the morphological changes, and examined the expression of browning markers in WAT and BAT during cold exposure.

\section{Materials and Methods}




\section{Animals and cold exposure}

Male C57Bl/6J mice purchased from the Medical Experimental Animal Center of Xi'an Jiaotong University, Shaanxi Province, China at 8 weeks of age were kept in a specific pathogen-free (SPF) environment. They were singly housed in conventional cages with a 12:12 h light-dark cycle with free access to water and standard chow diet (Beijing Keao Xieli Feed Co., Ltd.), containing $160 \mathrm{~g}$ of protein, $710 \mathrm{~g}$ of carbohydrates, and $30 \mathrm{~g}$ of lipid per $\mathrm{kg}$ of diet $(15204 \mathrm{~kJ} / \mathrm{kg})$. After one week of adaption, they were randomly divided into six groups; room temperature (RT), cold exposure (Cold) for $1,2,3,4,5$ and 7 days ( $\mathrm{n}=6$ for each group). Mice as Control group were all placed at $\mathrm{RT}\left(\approx 23^{\circ} \mathrm{C}\right)$ for 5 days, whilst the Cold groups were placed at $4^{\circ} \mathrm{C}$ for the abovementioned times. Diet and light conditions were identical among the six groups throughout the study. Body weight and food intake in both RT and Cold groups were measured daily. All procedures involving animals were performed in accordance with the Care and Use of Laboratory Animals published by the National Institutes of Health and the Ethical Committee of Xi'an Jiaotong University, China. All efforts were made to reduce animal discomfort and the number of animals used.

Mice were fasted for $4 \mathrm{~h}$, and blood was collected by retro-orbital bleed under isoflurane anesthesia. Plasma was obtained by centrifuging at $900 \mathrm{~g}$ at $4^{\circ} \mathrm{C}$ for $15 \mathrm{~min}$. The mice were subsequently sacrificed and the interscapular BAT (BAT), inguinal sWAT and epididymal WAT (eWAT) (Cinti 2005, Waldén et al. 2012) were removed, weighed and either frozen in liquid nitrogen for RNA and protein extraction, or fixed and stored in 4\% paraformaldehyde for hematoxylin-eosin (H\&E) staining and 
immumohistochemical evaluation.

\section{Plasma parameters and metabolite profiles}

Plasma triglycerides and cholesterol levels were measured using commercially available colorimetric assays performed following manufacturers' protocols (Beijing Puerweiye BioTech Co. Ltd., China). Blood from the tail vein was used to measure circulating glucose using OneTouch SureStep Test Strips (Johnson \& Johnson).

\section{RNA isolation and qRT-PCR analysis}

Total adipose mRNA was isolated using TRIzol reagent (Invitrogen, San Diego, $\mathrm{CA}, \mathrm{USA})$, and $1 \mu \mathrm{g}$ total mRNA per sample was reverse transcribed into cDNA using a commercial RT-PCR Kit according to the manufacturer's instructions (Thermo scientific, USA). Real time PCR was performed as previously described (Widberg et al. 2009). Relative expression of the gene of interest was determined using Cyclophilin as the housekeeping gene using the $-\Delta \Delta \mathrm{C}_{\mathrm{T}}$ method. All the primers were synthesized by AUGCT (Beijing, China). Sequences are shown in table 1.

\section{Western blot analysis}

Total adipose protein was extracted using RIPA buffer (Beyotime, China) according to the manufacturer's instructions, and concentration determined using the bicinchoninic acid (BCA) protein assay kit (Thermo scientific, USA). $15 \mu \mathrm{g}$ of protein was separated with $10 \%$ or $15 \%$ SDS-PAGE gels. Protein samples from each adipose depot were loaded on separate gels along with two representative BAT lysates from the RT group for standardization. Proteins were transferred onto polyvinylidenedifluoride membrane (Millipore). Membranes were blocked with 5\% 
nonfat dry milk in TBS containing $0.1 \%$ Tween for $1 \mathrm{~h}$ at room temperature. Membranes were then trimmed to narrow strips based on the molecular weight of the protein of interest according to the markers. These strips were then probed with an antibody to a single target protein. The membranes were incubated with the appropriate primary antibodies overnight at $4^{\circ} \mathrm{C}$. After washing, membranes were incubated with a secondary horseradish peroxidase (HRP)-coupled antibody and processed for enhanced chemiluminescence detection using Immobilon HRP substrate (Millipore). Signals were visualized and analyzed on a UVP VisionWorks LS BioSpectrum (USA). The intensity of bands was quantified using ImageJ Software (National Institute of Health, Bethesda, MD, USA). The ratio of the intensity of the target protein to that of $\beta$-tubulin loading control was calculated to represent the expression level of the protein. Antibodies were as follows: anti-PPAR $\gamma$ (1:500) (\#2435) (Cell Signaling Technology, Inc., USA), anti-aP2 (1:2,000) (sc-243921), anti-UCP-1 (1:500) (sc-6529) and anti- $\beta$-tubulin (1:1,000) (sc-9104) (Santa Cruz Biotechnology Inc., CA).

\section{Histology}

Tissue samples were fixed in $4 \%$ paraformaldehyde (PFA), dehydrated, and embedded in paraffin wax. $7 \mu \mathrm{m}$ sections were stained with $\mathrm{H} \& \mathrm{E}$ and assessed by light microscopy for morphology. Adipocyte diameter was measured using ImageJ Software (National Institute of Health, Bethesda, MD, USA). Data were collected from $H \& E$ stained sections from six mice in each group, five random fields per mouse, 20 40 cells per field at $400 \times$ magnification. UCP-1 immunohistochemistry was 
performed using a polyclonal anti-UCP-1 antibody. (Santa Cruz Biotechnology Inc., CA) (1:50) (sc-6529) Sections were examined by microscopy (BX53, Olympus, Tokyo, Japan).

\section{Statistical Analysis}

Statistical analyses were performed in GraphPad Prism 6.0 using One-way ANOVA (repeated measures) for differences across experimental groups in conjunction with Tukey post hoc test to compare differences between treatment groups. Data were expressed as means \pm S.E.M. $P$ values of $<0.05$ were considered statistically significant.

\section{Results}

\section{Dynamic changes of body weight, food intake and fat composition during cold}

\section{exposure}

To clarify the effect of cold exposure on basic metabolism in mice, studies were performed to compare mice maintained at room temperature (RT) or cold exposed (Cold) for up to five days. Preliminary experiments demonstrated no differences in morphology (S-Fig. 1a) and no significant changes to gene expression (S-Fig. 1b) between 1, 3 or 5 days spent at RT. Thus, all Cold data was compared to day 5 RT mice. The body weight of RT mice increased progressively throughout the study, whilst the body weight of Cold mice decreased by $20 \%$ in the first two days, before rebounding to the starting weight by day 4 . Relative to the RT mice, there was a significant difference in the body weight of the Cold mice on each day of the study 
(Fig. 1a). In addition, Cold mice displayed significantly higher food intake from day 2 of cold exposure than their counterparts at RT (Fig. 1b). We next wanted to determine whether cold exposure changed the morphology and mass of adipose tissues. We found the color of interscapular brown adipose tissue (iBAT) changed from a bright pink to a dark reddish hue during cold exposure (Fig 1c). Moreover, the subcutaneous adipose tissue (sWAT) and epididymal adipose tissue (eWAT) also acquired a reddish appearance after cold stimulation (Fig. 1c). iBAT mass was increased in the Cold mice from the third day of the treatment, whilst sWAT and eWAT mass was significantly reduced at days $1-3$, recovering thereafter. We calculated the total protein content of the adipose tissues in RT and Cold mice, and found this to closely reflect the adipose tissue weights (Fig. 1d-f). These changes were largely mirrored in the temporal changes in total adipose tissue as a percentage of body weight (Fig. 1g). These observations suggest that cold exposure promotes a coordinated response in BAT and WAT that includes a rapid and sustained increase in iBAT mass/browning, concomitant with a rapid decline in WAT mass simultaneous to WAT browning. Body weight declined in line with changes in WAT mass, recovering upon prolonged cold exposure. Blood lipid profiles showed that plasma triglycerides and cholesterol levels both declined significantly on the third day of cold treatment, rebounding slightly by day 4 (S-Fig.2a-b). Further, blood glucose levels dropped significantly during the first three days of cold treatment returning to RT levels on the fourth day (S-Fig. 2c). This data suggest that the temporal changes in blood lipids and glucose profiles are synchronized with body weight and fat mass. 


\section{Morphology changes of iBAT and WAT during cold exposure}

We next examined the temporal changes in morphology of iBAT, sWAT and eWAT of RT and Cold mice. Histological analysis revealed that the adipocytes in sWAT and eWAT of Cold mice at days 1-3 appeared smaller than those at RT. The lipid droplet size in the adipocytes iBAT was also markedly decreased (Fig. 2a). Quantitation of adipocyte size confirmed these observations, indicating that the proportion of small adipocytes was increased in iBAT and sWAT from day 1 (Fig. 2b). Despite failing to reach statistical significance, the eWAT tended to display a higher proportion of smaller adipocytes at days 1 and 2. Interestingly, adipocyte size in the eWAT reverted to baseline (RT) from day 3 onwards (Fig. 2b). These results indicate that cold exposure results in a rapid decrease in adipocyte size across iBAT, sWAT and eWAT, but this effect is not sustained in the latter.

Effect of cold exposure on expression of browning, mitochondrial and adipogenesis related genes

Given that cold exposure changed the mass and morphology of adipose tissues, we then investigated the temporal changes in BAT, sWAT, and eWAT gene expression. Various parameters including body and tissue weight, blood lipids and gene expression were comparable at day 5 and day 7 of cold acclimation (S-Fig. 3), suggesting the dynamic remodeling phase was largely limited to the first 5 days. Hence, we decided to focus on the remodeling of BAT and WAT in this dynamic phase for the remainder of the study. Expression of the core thermogenic gene, Ucp-1, exhibited a rapid and sustained up-regulation across all three depots. The Ucp-1 levels 
in iBAT were 4-fold higher than the highest levels in sWAT and 10000 times higher than in eWAT (Fig 3a(i)). Pgcl- $\alpha$, a key inducer of brown adipocyte activation, was also increased within 1 day of cold stimulation, although this tended to decrease on subsequent days whilst remaining significantly higher than that of the RT group (Fig 3a(ii)). We also found that expression of Elovl3, a marker of brown adipocytes, was rapidly induced by cold exposure in all three depots, peaking at day 1 in iBAT and eWAT but at day 4 in sWAT (Fig 3a(iii)). Interestingly, the changes in the expression profile of Cidea differed in each of the depots (Fig 3a(iv)). In iBAT, Cidea expression was decreased by around $20 \%$ across all time points. In sWAT, it increased gradually over time, peaking at around 5-fold on day 4. In eWAT, Cidea was increased 4-fold at day 1 and decreased thereafter. These data demonstrate that cold exposure induces the expression of browning markers in all depots, however, the relative expression of these markers, the magnitude of the changes and the temporal profiles differed across the depots.

Having detailed the temporal depot-specific induction profiles of Ucp-1 and Pgcl- $\alpha$ following cold exposure, we extended our investigation to examine markers of mitochondrial biogenesis and function (Fig. 3b). Cox7al, which is involved in mitochondrial oxidative phosphorylation, was upregulated in iBAT, sWAT, and eWAT from day 3 of cold exposure (Fig. 3b(i)). Another mitochondrial biogenesis marker, Cox $8 b$, showed a similar expression pattern to Cox $7 a 1$ in both sWAT and eWAT (Fig. 3b(ii)). Perhaps surprisingly, Cox $8 b$ expression in iBAT was transiently decreased in Cold mice, reaching a nadir at day 2. As expected, the expression levels of both 
browning and mitochondrial genes were highest in iBAT and lowest in eWAT.

Having observed cold-induced changes in adipose tissue mass, we investigated whether cold exposure was associated with changes in expression of genes associated with adipogenesis or fat cell function (Fig. 3c). Interestingly, cold exposure induced a transient decrease in expression of Ppary, the master adipogenic regulator, in iBAT and sWAT at day 4 and day 2 respectively with no significant change observed in eWAT. The expression of $a P 2$ was rapidly induced in iBAT and eWAT, peaking at day 4 and day 1 respectively, whilst it was unchanged in sWAT. Changes in expression of the glucose transporter Glut1, which is responsible for basal (non-insulin) mediated glucose uptake and is usually high in preadipocytes compared to adipocytes, differed markedly across the depots. In iBAT Glut1 levels were increased around 2-fold at days 1-2 before decreasing to levels below baseline at days 4-5 (Fig. 3c(iii)). In contrast, sWAT Glut1 levels remained stable until day 3 when they increased 3-4-fold. Finally, Glut1 levels in eWAT were decreased by more than $90 \%$ from day 3 onwards (Fig. 3c(iii)). The other major glucose transporter that is expressed in mature adipocytes is the insulin-responsive glucose transporter Glut4. Cold exposure did not change the expression of Glut4 in iBAT, whilst the changes in sWAT were similar to those observed for Glut1 (Fig. 3c(iv)). In eWAT, cold exposure induced a brief increase Glut4 at day 1. The expression of Cyclophilin in the adipose tissues at different time points did not change (Fig.3d). Collectively, these differences in cold-induced changes in gene expression profiles reinforce the notion that remodeling of adipose tissues in response to cold exposure occurs in a depot-specific manner. 


\section{Effect of cold exposure on UCP-1, PPAR $\gamma$ and aP2 protein levels}

To extend our observations at the gene level we characterized the effects of cold exposure on changes of the proteins UCP-1, PPAR $\gamma$ and aP2. Consistent with gene expression, histology and Western blot analysis demonstrated that UCP-1 protein was expressed constitutively in iBAT and this was increased during cold exposure (Fig. 4a-c). Histology and Western blot analysis revealed low to undetectable levels of UCP-1 protein in both sWAT and eWAT at baseline (RT) with sustained induction of UCP-1 protein visible from day 1 . UCP-1 induction was slightly higher in sWAT than eWAT. Importantly, the amount of UCP-1 protein in iBAT was $10-20$-fold of that in sWAT and eWAT (Fig. 4a-c). Interestingly, changes in PPAR $\gamma$ and aP2 protein levels did not reflect the changes observed in gene expression. In iBAT, PPAR $\gamma$ and aP2 protein levels were unchanged by cold exposure (Fig. 4b-c). PPAR $\gamma$ protein was increased in both sWAT and eWAT on day $1 \& 2$ and continued to rise, whilst aP2 protein was increased from day 2 onwards in both depots (Fig. 4b-c). These differences in cold-induced changes in protein profiles highlight the potential for discordance between gene expression and protein, and further reinforce the notion that cold-induced remodeling of adipose tissue exhibits depot-specificity.

In an attempt to evaluate the potential thermogenic capacity of each depot during the period of cold-exposure-induced remodeling, we estimated total UCP-1 protein content within each depot by considering the increase in depot protein (shown in Figs 1d-f) and the relative increase in UCP-1 protein (shown in Fig 4c). This analysis revealed total UCP-1 content in iBAT was increased throughout the entire period of 
cold exposure, peaking by 6 -fold on day 4 (Fig 5a). While total UCP-1 content was also increased in sWAT and eWAT by around 6-fold and 4-fold respectively, total UCP-1 content was significantly reduced during the early period of cold adaptation (Fig $5 \mathrm{~b} \& \mathrm{c}$ ), reflecting the decrease in depot size. We also combined the results from the three depots to provide insight into the potential contribution of each to total thermogenic capacity. This final analysis revealed how the contribution from iBAT represented greater than $90 \%$ of total UCP-1 content (Fig. 5d), highlighting that the changes in iBAT are likely to be much more important to total thermogenic capacity than the changes in eWAT or sWAT.

\section{Discussion}

The potential of BAT to combat obesity through increased energy expenditure, combined with recent reports demonstrating the presence of functional BAT and beige adipocytes in adult humans (Nedergaard et al. 2007, Lee et al. 2010, Lee et al. 2011, Lee et al. 2014a, Lee et al. 2014b), has stimulated renewed interest in understanding the development and function of brown and beige adipocytes (Bordicchia et al. 2012, Bostrom et al. 2012, Cederberg et al. 2001, Seale et al. 2011). Recent studies have shown that cold exposure is a dominant regulator of BAT and beige adipocyte development and function. Although an earlier study in rat adipose tissues demonstrated regional differences in gene expression (Cousin et al. 1993), it remains poorly understood as to what extent adipose tissue remodeling and browning in BAT and WAT exhibits depot-specific differences. We have addressed this by 
characterizing the temporal changes induced by prolonged cold exposure in adipose tissue architecture and gene and protein profiles in mouse BAT and WAT compared with 5 days of room temperature (RT). We have shown that cold exposure rapidly increased activation of iBAT and this was companied by an increase in iBAT mass. We observed a rapid, transient decrease in sWAT and eWAT mass, which was reversed upon continued cold exposure, and was concomitant with activation of browning in these depots. Thus, exposure to cold induced a transformation process comprised of two major phases; an early 'cold remodeling' phase (days 1-3) and a later 'cold adapted' phase (days 4-5), which is further supported by body weight and blood lipid analyses.

We found that cold exposure induced a rapid increase in indicators of BAT activity and iBAT mass (becoming significant at day 3 ) in the context of increased food-intake, reduced body weight, sWAT and eWAT mass. These observations are entirely consistent with a rapid increase in parameters, including increased thermogenic capacity and substrate availability via increased lipolysis and food intake, to increase energy expenditure and maintain body temperature (Ravussin et al. 2014, Ukropec et al. 2006, Vaanholt et al. 2009). Our finding of a net reduction in body weight during the first 3 days of cold exposure is in line with a previous study that found significantly decreased body weight in mice subjected to 3 days cold exposure (Wang et al. 2013). We observed a return to starting body weight in the Cold mice after 4 days, which is consistent with other studies that demonstrated no change in body weight following similar, prolonged periods of cold exposure (Barnett 1965, Ravussin 
et al. 2014). It is noteworthy, however, that the Cold mice remained lighter than the control mice at all time points.

Cold exposure induced multiple early changes in BAT consistent with increased mobilization and utilization of lipid to fuel thermogenesis. Furthermore, average

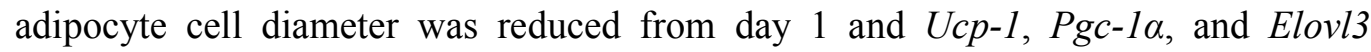
expression were all elevated, as was UCP-1 protein. Interestingly Cidea expression exhibited a rapid and sustained decrease upon cold exposure. Given that Cidea deficiency has been shown to increase lipolysis in BAT (Zhou et al. 2003), it is tempting to speculate that the reduction in Cidea also contributes to increased lipolysis in the cold-stimulated iBAT. Paradoxically some, but not all (Barneda et al. 2013, Fisher et al. 2012), studies have reported increased Cidea expression in iBAT after 1-3 days of cold exposure (Barbatelli et al. 2010, Wang et al. 2013). The discrepancy between our results and those of Barbatelli et al. may arise from protocol differences. In contrast to Barbatelli et al., we fasted our mice for 4 hours before tissue collection, which was performed following brief inhalation anesthesia. However, a 4 hour fast during the inactive phase is generally considered a very minor intervention, and should not generate a condition of energy deficiency (Gaultier et al 2009, Giannulis et al 2014). Therefore, the reasons for these discordant observations remain unclear, but are more likely to be attributed to the different gender and strain of mice used (female 129Sv mice versus male C57BL/6J mice). The increase in iBAT mass and reduction in adipocyte cell size support the notion of de novo differentiation of adipocytes (Bukowiecki et al. 1982). However, whilst we observed increased 
expression of the adipogenic marker $a P 2$ from day 1 , we did not detect increased $a P 2$ at the protein level. We also observed a transient decrease of Ppar $\gamma$ gene expression, which was consistent with an earlier report (Yu et al. 2002), but a decrease in PPAR $\gamma$ protein was not observed. This discrepancy might be attributed to the pre-translational control in mRNA and the level of the ensuing protein product induced by cold acclimation (Jacobsson et al. 1994). Hence, further studies are necessary to determine the extent to which the generation of new brown adipocytes contributes to cold-induced iBAT expansion. Interestingly, although there was no change in Glut4 mRNA, we did observe a significant increase of Glut1 mRNA upon cold exposure in iBAT. It has previously been shown that norepinephrine induces a potent increase in Glut1 mRNA expression and a decrease in Glut4 mRNA expression in primary brown adipocytes (Dallner et al. 2006). Moreover, adrenergic stimulation in brown adipocytes induces glucose uptake via a mechanism independent of GLUT4 and GLUT1 translocation but instead involving de novo synthesis and increase of GLUT1 protein at the plasma membrane (Dallner et al. 2006). It is possible that cold exposure also utilizes this mechanism. Interestingly, we also saw a significant decrease of Glut1 in iBAT from 4 days of cold exposure. It is possible that during cold adaptation, sWAT becomes more dominant with regards to glucose uptake. Consistent with this notion, the expression of Glut1 and Glut4 was increased in sWAT from 3 days of cold exposure.

Emerging evidence suggests that beige cells expressing UCP-1 become more prominent within sWAT in mice and humans after cold exposure (Vitali et al. 2012, 
Lee et al. 2014b). Consistent with this, our study showed cold exposure induced rapid browning of sWAT, indicated by a large increase in the expression of markers of


$U C P$-1-positive cell staining with subsequent increases in expression of Cox $7 a 1$ and Cox $8 b$, markers of mitochondrial oxidative phosphorylation. Interestingly, the levels of PPAR $\gamma$ and aP2 protein were increased persistently from 1 and 2 days of cold exposure respectively. These observations are consistent with those from a previous study which showed that 3 days of cold exposure induced beige adipogenesis in sWAT (Wang et al. 2013).

Our studies also reveal that eWAT is only very modestly and slowly responsive to cold stimuli. The current notion in the field is that eWAT is relatively non-responsive to adrenergic stimulation. Our studies support this view when the extent of cold-induced browning of eWAT is compared with that of sWAT (for example, Ucp-1 expression in eWAT is much lower than in sWAT). Nevertheless, most browning markers were significantly up regulated in eWAT upon cold exposure, and protein levels of PPAR $\gamma$ and aP2 (but not mRNA) were increased in eWAT. This did not appear to reflect a major increase in adipocyte cell number as changes in eWAT mass and adipocyte size were both transiently reduced, returning to control levels after 4-5 days cold exposure. Collectively, these observations support the notion that there may be relatively chronic and mild turnover of adipocytes in this depot in response to prolonged cold-exposure. Moreover, such newly differentiated adipocytes would be predominantly white. Such a scenario is largely in agreement 
with a study by Wang et al., who reported that cold exposure resulted in the de novo development of white adipocytes in gonadal WAT (Wang et al. 2013). In addition, recent report, which demonstrated that there were different mechanisms for browning in sWAT and iBAT, at least from one side, supported our observations in eWAT (Lee et al. 2015).

It is noteworthy that the temperature of a normal animal house $\left(20^{\circ} \mathrm{C}\right.$, as well as $24^{\circ} \mathrm{C}$ ) can in itself represent a moderate cold stress (Nedergaard \& Cannon 2014), prompting suggestions that a thermoneutral group should be added to control for the effect of physical activity and the possible thermic effect of the food in cold acclimation studies. However, a recent study reported that in studies of mice at temperatures below thermoneutrality, the differences in activity are unlikely to explain the differences in energy expenditure between different groups (Virtue et al. 2012). What's more, another study indicated that the gene transcripts changing in BAT and liver between room temperature and thermoneutral housed mice in response to cold were similar, whereas there were far fewer changes in WAT, and these genes did not overlap with those changed in either BAT or liver (Shore et al. 2013). Thus, we consider it reasonable to set the RT group as a reference to characterize the temporal profile of cold-induced changes and browning of brown and white adipose tissue in mice.

It is known that mammals shiver to generate heat to maintain body temperature when acutely exposed to a cold environment, whilst prolonged cold exposure induces the browning process in adipose tissue. Thus, shivering is replaced with adaptive 
non-shivering thermogenesis which increases heat production through the activation of UCP-1. What's more, this adaptive thermogenesis is more pronounced during the prolonged cold acclimation (Aydin et al. 2008). Therefore, understanding the morphology and molecular biology of adipose tissue 'browning' during cold exposure is necessary for the development of its therapeutic potential for the treatment of obesity and metabolic disease.

The presented data demonstrates that white adipose tissues display dynamic alteration regarding morphology and the expression of browning markers during cold exposure. On this basis we propose that the process of cold acclimation initially induces a phase of cold remodeling, where sWAT and eWAT display a reduction in cell diameter and fat mass consistent with providing a fuel substrate to meet increased energy demands. Subsequently, cold adaptation is achieved, manifested as a reversal in weight loss and lipid profile decline. BBAT was rapidly activated in the early stage of cold exposure, and continued to significantly contribute to the thermogenic process throughout cold acclimation. Our analysis of total UCP-1 content is consistent with a model whereby iBAT represents the major contributor to thermogenic capacity $(>90 \%)$ with sWAT and eWAT contributing only relatively modest amounts $(<7$ and $<3 \%$ respectively). Collectively, this study demonstrates that iBAT is highly responsive to cold exposure, and is supported mainly by the browning of sWAT, and to a lesser extent eWAT. This coordinated process enables animals to undergo cold-induced remodeling to achieve a cold-adapted homeostasis. 


\section{Acknowledgment}

This work was supported by: grant 31200886 (to Xiao Luo) from the National Natural

Science Foundation of China; grant to Xiao Luo from the Fundamental Research Funds for the Central Universities (2012jdhz61): grant from the Australian National Health and Medical Research Council (1047625); and grant from the China Postdoctoral Science Foundation (2015M580856). The Translational Research Institute is supported by a grant from the Australian Government.

\section{Conflict of Interest}

The authors declare that there are no dualities of interest with this study. 


\section{References}

Atit, R., Sgaier, S. K., Mohamed, O. A., Taketo, M. M., Dufort, D., Joyner, A. L., Niswander, L. \& Conlon, R. A. 2006. beta-catenin activation is necessary and sufficient to specify the dorsal dermal fate in the mouse. Dev Biol 296, 164-176.

Aydin, J., Shabalina, I. G., Place, N., Reiken, S., Zhang, S. J., Bellinger, A. M., Nedergaard, J., Cannon, B., Marks, A. R., Bruton, J. D. \& Westerblad, H. 2008. Nonshivering thermogenesis protects against defective calcium handling in muscle. Faseb $J$ 22, 3919-3924.

Barbatelli, G., Murano, I., Madsen, L., Hao, Q., Jimenez, M., Kristiansen, K., Giacobino, J. P., De Matteis, R.. \& Cinti, S. 2010. The emergence of cold-induced brown adipocytes in mouse white fat depots is determined predominantly by white to brown adipocyte transdifferentiation. Am J Physiol Endocrinol Metab 298, E1244-253.

Barneda, D., Frontini, A., Cinti, S. \& Christian, M. 2013. Dynamic changes in lipid droplet-associated proteins in the "browning" of white adipose tissues. Biochim Biophys Acta 1831, 924-933.

Barnett, S. A. 1965. Adaptation of Mice to Cold. Biol Rev Camb Philos Soc 40, 5-51.

Bordicchia, M., Liu, D., Amri, E. Z., Ailhaud, G., Dessi-Fulgheri, P., Zhang, C., Takahashi, N., Sarzani, R., \& Collins, S. 2012. Cardiac natriuretic peptides act via p38 MAPK to induce the brown fat thermogenic program in mouse and human adipocytes. $J$ Clin Invest 122, 1022-1036.

Bostrom, P., Wu, J., Jedrychowski, M. P., Korde, A., Ye, L., Lo, J. C., Rasbach, K. A., Bostrom, E. A., Choi, J. H., Long, J. Z., Kajimura, S., Zingaretti, M. C., Vind, B. F., Tu, H., Cinti, S., Hojlund, K. et al. 2012. A PGC1-alpha-dependent myokine that drives brown-fat-like development of white fat and thermogenesis. Nature 481, 463-468.

Bukowiecki, L., Collet, A. J., Follea, N., Guay, G., \& Jahjah, L. 1982. Brown adipose tissue 
hyperplasia: a fundamental mechanism of adaptation to cold and hyperphagia. Am J Physiol 242, E353-359.

Cannon, B., \& Nedergaard, J. 2004. Brown adipose tissue: function and physiological significance. Physiol Rev 84, 277-359.

Cannon, B., \& Nedergaard, J. 2011. Nonshivering thermogenesis and its adequate measurement in metabolic studies. J Exp Biol 214, 242-253.

Cao, L., Choi, E. Y., Liu, X., Martin, A., Wang, C., Xu, X. \& During, M. J. 2011. White to brown fat phenotypic switch induced by genetic and environmental activation of a hypothalamic-adipocyte axis. Cell Metab 14, 324-338.

Cederberg, A., Gronning, L. M., Ahren, B., Tasken, K., Carlsson, P. \& Enerback, S. 2001. FOXC2 is a winged helix gene that counteracts obesity, hypertriglyceridemia, and diet-induced insulin resistance. Cell 106, 563-573.

Cinti, S. 2005. The adipose organ. Prostaglandins Leukot Essent Fatty Acids 73, 9-15.

Cousin, B., Casteilla, L., Dani, C., Muzzin, P., Revelli, J. P. \& Penicaud, L. 1993. Adipose tissues from various anatomical sites are characterized by different patterns of gene expression and regulation. Biochem. J 292, 873-876.

Cousin, B., Cinti, S., Morroni, M., Raimbault, S., Ricquier, D., Penicaud, L., \& Casteilla, L. 1992. Occurrence of brown adipocytes in rat white adipose tissue: molecular and morphological characterization. J Cell Sci 103, 931-942.

Dallner, O. S., Chernogubova, E., Brolinson, K. A., \& Bengtsson, T. 2006. Beta3-adrenergic receptors stimulate glucose uptake in brown adipocytes by two mechanisms independently of glucose transporter 4 translocation. Endocrinology 147, 5730-5739. 
Fisher, F. M., Kleiner, S., Douris, N., Fox, E. C., Mepani, R. J., Verdeguer, F., Wu, J., Kharitonenkov, A., Flier, J. S., Maratos-Flier, E. \& Spiegelman, B. M. 2012. FGF21 regulates PGC-1 alpha and browning of white adipose tissues in adaptive thermogenesis. Genes Dev 26, 271-281.

Gautier, E. L., Huby, T., Saint-Charles, F., Ouzilleau, B., Pirault, J., Deswaerte, V., Ginhoux, F., Miller, E. R., Witztum, J. L., Chapman, M. J. \& Lesnik, P. 2009. Conventional dendritic cells at the crossroads between immunity and cholesterol homeostasis in atherosclerosis. Circulation 119, $2367-2375$.

Gesta, S., Tseng, Y. H., \& Kahn, C. R. 2007. Developmental origin of fat: tracking obesity to its source. Cell 131, 242-256.

Giannulis, I., Mondini, E., Cinti, F., Frontini, A., Murano, I., Barazzoni, R., Barbatelli, G., Accili, D. \& Cinti, S. 2014. Increased density of inhibitory noradrenergic parenchymal nerve fibers in hypertrophic islets of langerhans of obese mice. Nutr Metab Cardiovas 24, 384-392.

Ishibashi, J., \& Seale, P. 2010. Beige can be slimming. Science 328, 1113-1114

Jacobsson, A., Mühleisen, M., Cannon, B. \& Nedergaard, J. 1994. The uncoupling protein thermogenin during acclimation: indications for pretranslational control. Am J Physiol 267, 999-1007.

Jakus, P. B., Sandor, A., Janaky, T., \& Farkas, V. 2008. Cooperation between BAT and WAT of rats in thermogenesis in response to cold, and the mechanism of glycogen accumulation in BAT during reacclimation. J Lipid Res 49, 332-339.

Lee, P., Greenfield, J. R., Ho, K. K. \& Fulham, M. J. 2010. A critical appraisal of the prevalence and metabolic significance of brown adipose tissue in adult humans. Am J Physiol Endocrinol Metab 299, E601-6. 
Lee, P., Smith, S., Linderman, J., Courville, A. B., Brychta, R. J., Dieckmann, W., Werner, C. D., Chen, K. Y. \& Celi, F. S. 2014a. Temperature-acclimated brown adipose tissue modulates insulin sensitivity in humans. Diabetes 63, 3686-98.

Lee, P., Werner, C. D., Kebebew, E. \& Celi, F. S. 2014b. Functional thermogenic beige adipogenesis is inducible in human neck fat. Int J Obes 38, 170-6.

Lee, P., Zhao, J. T., Swarbrick, M. M., Gracie, G., Bova, R., Greenfield, J. R., Freund, J. \& Ho, K. K. 2011. High prevalence of brown adipose tissue in adult humans. J Clin Endocrinol Metab 96, 2450-5.

Lee, Y. H., Petkova, A. P., Konkar, A. A. \& Granneman, J. G. 2015. Cellular origins of cold-induced brown adipocytes in adult mice. Faseb $J$ 29, 286-99.

Lepper, C. \& Fan, C. 2010. Inducible lineage tracing of pax7-descendant cells reveals embryonic origin of adult satellite cells. Genesis 48, 424-436.

Nakamura, Y., Sato, T., Shiimura, Y., Miura, Y. \& Kojima, M. R. N. 2013. FABP3 and brown adipocyte-characteristic mitochondrial fatty acid oxidation enzymes are induced in beige cells in a different pathway from UCP1. Biochem Biophys Res Commun 441,42-46.

Nedergaard ,J., Bengtsson, T. \& Cannon, B. 2007. Unexpected evidence for active brown adipose tissue in adult humans. Am J Physiol Endocrinol Metab 293, E444-52.

Nedergaard, J., \& Cannon, B. 2014. The browning of white adipose tissue: some burning issues. Cell Metab 20, 396-407.

Petrovic, N., Walden, T. B., Shabalina, I. G., Timmons, J. A., Cannon, B. \& Nedergaard, J. 2010. Chronic peroxisome proliferator-activated receptor gamma (PPAR gamma) activation of epididymally derived white adipocyte cultures reveals a population of thermogenically 
competent, UCP1-containing adipocytes molecularly distinct from classic brown adipocytes. $J$ Biol Chem 285, 7153-7164.

Ravussin, Y., Xiao, C., Gavrilova, O. \& Reitman, M. L. 2014. Effect of intermittent cold exposure on brown fat activation, obesity, and energy homeostasis in mice. PLoS One 9, e85876.

Robidoux, J., Martin, T. L. \& Collins, S. 2004. Beta-adrenergic receptors and regulation of energy expenditure: a family affair. Annu Rev Pharmacol Toxicol 44, 297-323.

Sanchez-Gurmaches, J. \& Guertin, D. A. 2014. Adipocytes arise from multiple lineages that are heterogeneously and dynamically distributed. Nat Commun 5, 4099-4099.

Sanchez-Gurmaches, J., Hung, C. M., Sparks, C. A., Tang, Y. F., Li, H. W. \& Guertin, D. A. 2012. PTEN loss in the Myf5 lineage redistributes body fat and reveals subsets of white adipocytes that arise from Myf5 precursors. Cell Metab 16, 348-362.

Schulz, T. J., Huang, P., Huang, T. L., Xue, R., McDougall, L. E., Townsend, K. L., Cypess, A. M., Mishina, Y., Gussoni, E. \& Tseng, Y. H. 2013. Brown-fat paucity due to impaired BMP signalling induces compensatory browning of white fat. Nature 495, 379-383.

Seale, P., Bjork, B., Yang, W., Kajimura, S., Chin, S., Kuang, S., Scime, A., Devarakonda, S., Conroe, H. M., Erdjument-Bromage, H., Tempst, P., Rudnicki, M. A., Beier, D. R. \& Spiegelman, B. M. 2008. PRDM16 controls a brown fat/skeletal muscle switch. Nature 454, 961-967.

Seale, P., Conroe, H. M., Estall, J., Kajimura, S., Frontini, A., Ishibashi, J., Cohen, P., Cinti, S. \& Spiegelman, B. M. 2011. Prdm16 determines the thermogenic program of subcutaneous white adipose tissue in mice. J Clin Invest 121, 96-105.

Shefer, V. I. \& Talan, M. I. 1997. The effect of exercise training in a cold environment on thermoregulation in adult and aged C57BL/6J mice. Exp Gerontol 32, 695-705. 
Shore, A. M., Karamitri, A., Kemp, P., Speakman, J. R., Graham, N. S. \& Lomax, M. A. 2013. Cold-induced changes in gene expression in brown adipose tissue, white adipose tissue and liver. PLoS One 8, e68933.

Stephens, M., Ludgate, M. \& Rees, D. A. 2011. Brown fat and obesity: the next big thing? Clin Endocrinol (Oxf) 74, 661-670.

Timmons, J. A., Wennmalm, K., Larsson, O., Walden, T. B., Lassmann, T., Petrovic, N., Hamilton, D. L., Gimeno, R. E., Wahlestedt, C., Baar, K., Nedergaard, J. \& Cannon, B. 2007. Myogenic gene expression signature establishes that brown and white adipocytes originate from distinct cell lineages. PNAS 104, 4401-4406.

Ukropec, J., Anunciado, R. P., Ravussin, Y., Hulver, M. W. \& Kozak, L. P. 2006. UCP1-independent thermogenesis in white adipose tissue of cold-acclimated Ucp1-/- mice. J Biol Chem 281, 31894-31908.

Vaanholt, L. M., Daan, S., Schubert, K. A. \& Visser, G. H. 2009. Metabolism and aging: effects of cold exposure on metabolic rate, body composition, and longevity in mice. Physiol Biochem Zool $82,314-324$.

Vernochet, C., McDonald, M. E. \& Farmer, S. R. 2010. Brown adipose tissue: a promising target to combat obesity. Drug News Perspect 23, 409-417.

Virtue, S., Even, P. \& Vidal, A. 2012. Below thermoneutrality, changes in activity do not drive changes in total daily energy expenditure between groups of mice. Cell Metab 16, 665-671.

Vitali, A., Murano, I., Zingaretti, M. C., Frontini, A., Ricquier, D. \& Cinti, S. 2012. The adipose organ of obesity-prone C57BL/6J mice is composed of mixed white and brown adipocytes. J Lipid Res 53, 619-629. 
Waldén, T. B., Hansen, I. R., Timmons, J. A., Cannon, B. \& Nedergaard, J. 2012. Recruited vs. nonrecruited molecular signatures of brown, "brite," and white adipose tissues. Am J Physiol Endocrinol Metab, 302, E19-31.

Wang, Q. A., Tao, C., Gupta, R. K. \& Scherer, P. E. 2013. Tracking adipogenesis during white adipose tissue development, expansion and regeneration. Nat Med 10, 1338-1344.

Widberg, C. H., Newell, F. S., Bachmann, A. W., Ramnoruth, S. N., Spelta, M. C., Whitehead, J. P., Hutley, L. J. \& Prins, J. B. 2009. Fibroblast growth factor receptor 1 is a key regulator of early adipogenic events in human preadipocytes. Am J Physiol Endocrinol Metab 296, E121-131.

Xue, B., Coulter, A., Rim, J. S., Koza, R. A. \& Kozak, L. P. 2005. Transcriptional synergy and the regulation of Ucp1 during brown adipocyte induction in white fat depots. Mol Cell Biol 25, 8311-8322.

Yoo, H. S., Qiao, L., Bosco, C., Leong, L. H., Lytle, N., Feng, G. S., Chi, N. W. \& Shao, J. 2014. Intermittent cold exposure enhances fat accumulation in mice. PLoS One 9, e96432.

Yu, J., Zhang, S., Cui, L., Wang, W., Na, H., Zhu, X., Li, L., Xu, G., Yang, F., Christian, M. \& Liu, P. 2015. Lipid droplet remodeling and interaction with mitochondria in mouse brown adipose tissue during cold treatment. Biochim Biophys Acta 1853, 918-928.

Yu, X. X., Lewin, D. A., Forrest, W. \& Adams, S. H. 2002. Cold elicits the simultaneous induction of fatty acid synthesis and beta-oxidation in murine brown adipose tissue: prediction from differential gene expression and confirmation in vivo. Faseb $J 16,155-168$.

Zhou, Z., Yon Toh, S., Chen, Z., Guo, K., Ng, C. P., Ponniah, S., Lin, S. C., Hong, W. \& Li, P. 2003. Cidea-deficient mice have lean phenotype and are resistant to obesity. Nat Genet 35, 49-56. 
Table 1. Primers used for quantitative real-time PCR analysis.

\begin{tabular}{lllc}
\hline Gene & Forward primer & Reverse primer & Size $(\mathrm{bp})$ \\
\hline Ucp-1 & CTGCCAGGACAGTACCCAAG & TCAGCTGTTCAAAGCACACA & 148 \\
Pgc-1 $\alpha$ & CCCTGCCATTGTTAAGACC & TGCTGCTGTTCCTGTTTC & 161 \\
Elovl3 & GGACTTAAGGCCCTTTTTGG & TTCCGCGTTCTCATGTAGGT & 105 \\
Cidea & ATCACAACTGGCCTGGTTACG & TACTACCCGGTGTCCATTTCT & 136 \\
Ppary & GTACTGTCGGTTTCAGAAGTGCC & ATCTCCGCCAACAGCTTCTCCT & 102 \\
aP2 & GATGCCTTTGTGGGAACCT & CTGTCGTCTGCGGTGATTT & 230 \\
Glut1 & GCTTCTCCAACTGGACCTCAAAC & ACGAGGAGCACCGTGAAGATGA & 103 \\
Glut4 & TGATTCTGCTGCCCTTCTGT & GGACATTGGACGCTCTCTCT & 173 \\
Cox7al & GGGAATGGACAACGTCCTGT & GCCCAGCCCAAGCAGTATAA & 84 \\
Cox8b & CCGAGAATCATGCCAAGGCT & GTGGGCTAAGACCCATCCTG & 189 \\
Cyclophlin & CATACAGGTCCTGGCATCTTGTC & AGACCACATGCTTGCCATCCAG & 112 \\
\hline
\end{tabular}




\section{Figure Legends}

Fig.1Dynamic changes of body weight, food intake and fat composition during cold exposure. (a) Change in body weight (\%) of control (Room Temperature, RT) and cold-exposed (Cold) mice. Mice were weighed daily during the experiment. The $\%$ decrease in body weight was calculated based on the measurement immediately before the cold exposure. The age-matched mice living in the room temperature were used as controls. All data are presented as mean \pm standard error of the mean(S.E.M.)*P< $0.05, * * P<0.01,{ }^{* * * P}<0.001$ compared to the data at the beginning of the treatment in each group, ${ }^{\#} P<0.05,{ }^{\# \#} P<0.01,{ }^{\# \#} P<0.001$ for Cold compared to the control group. (b) Daily food intake per mouse of RT and Cold exposure group. (c) Morphologies of iBAT, sWAT, and eWAT in control and cold-exposed mice at different time points during the cold exposure. iBAT(d), sWAT(e) and eWAT(f) weights and total protein of mice living in the room temperature and in the cold environment after 1, 2, 3, 4, 5 or 7 days. (g) The compositional proportion (percentage of fat pad weight relative to the whole body weight) of iBAT, sWAT and eWAT from RT and Cold mice ( $n=6$ for each group).All data are presented as mean \pm S.E.M. $* P<0.05, * * * P<0.001$ for Cold compared to the control group for the total of the adipose tissues.

Fig.2 Morphology changes of iBAT and WAT during cold exposure. (a) H\&E staining of iBAT, sWAT and eWAT from RT and Cold mice (Magnification: 400×, Scale bar: $100 \mu \mathrm{m}$ ). (b) Quantification of adipocyte diameter of iBAT, sWAT and 
eWAT from RT and Cold mice. (Data were collected from H\&E-stained sections of six individual mice in each group, five fields per mouse, $20 \sim 40$ cells per field, using ImageJ software).

Fig.3 Effect of cold exposure on expression of browning, mitochondrial and adipogenesis related genes. Quantitative PCR analysis of browning (a), mitochondrial (b) and adipogenesis (c) related genes, as well as the reference (d) gene expression in iBAT, sWAT and eWAT of RT mice and Cold mice $\left(4^{\circ} \mathrm{C}\right)$ for up to $5 \mathrm{~d}$. The data show the fold changes of the expression for the target genes in iBAT, sWAT and eWAT of RT and Cold mice ( $\mathrm{n}=6$ for each group). Values are mean \pm S.E.M. and expression of genes is corrected for the housekeeping gene Cyclophilin. All the data were normalized to the expression in eWAT of RT mice respectively to indicate the inter-depot gene expression differences. $\left({ }^{*} P<0.05,{ }^{*} P<0.01, * * * P<0.001\right)$

Fig.4 Effect of cold exposure on UCP-1, PPAR $\gamma$ and aP2 protein levels. (a) UCP-1 immunohistochemical staining of BBAT, sWAT and eWAT from RT and Cold mice. Immunohistochemical analysis showed higher expression of UCP-1 protein in the cold treated group, as the extension of processing time. (Magnification: $400 \times$, Scale bar: $100 \mu \mathrm{m})(\mathbf{b})$ Western blot analysis for UCP-1, PPAR $\gamma$ and aP2 using total protein isolated from iBAT, sWAT and eWAT for RT and Cold mice. Reference iBAT samples are included with sWAT and eWAT samples labelled as SS (standard samples). (c) Quantification of Western blot analysis. Protein content is expressed relative to the 
control and represents three similar independent experiments with triplicate observations in each experiment. Volume is the sum of all pixel intensities within a band. All data are normalized to $\beta$-tubulin and are expressed as mean \pm S.E.M ( $n=6$ for each group). The expression levels of the protein were normalized to that expression in iBAT of RT mice respectively to indicate the inter-depot protein expression differences. $\quad(* P<0.05, * * P<0.01, * * * P<0.001)$

Fig.5 Effect of cold exposure on total UCP-1 protein content. Relative UCP-1 protein content was calculated by considering total depot size (protein) and relative UCP-1 protein levels. Graphs (a-c) show fold-change in UCP-1 protein content in iBAT (a), sWAT (b) and eWAT (c) upon cold exposure $\left(4^{\circ} \mathrm{C}\right)$ for up to $5 \mathrm{~d}$ with data normalized to RT mice (set at 1 for each depot). Graph (d) shows the combined fold-change in UCP-1 protein content across all three depots with the contribution of each depot as indicated (levels of UCP-1 protein were normalized to that in iBAT of RT mice). $\left({ }^{*} P<0.05,{ }^{* *} P<0.01, * * * P<0.001\right)$ All data are presented as mean \pm S.E.M. ( $\mathrm{n}=6$ for each group).

\author{
S-Fig.1 Morphology and gene expression of iBAT and sWAT at different time \\ points in room temperature. (a) $\mathrm{H} \& \mathrm{E}$ and UCP-1 immunohistochemical staining of \\ iBAT and sWAT from mice after 1,3 and 5 day living at room temperature(RT) \\ (Magnification: 400×, Scale bar: $20 \mu \mathrm{m}$ ). (b) Quantitative PCR analysis of Ucp-1, \\ Pgc-1 $\alpha$ and Elovl3 gene expression in BBAT and sWAT of mice living at the room
}


temperature for 1,3 and 5 days. The data show the $2^{\wedge(\text { CtRef Gene-CtGOI) }}$ values of target genes in iBAT and sWAT of mice at different time points at RT ( $\mathrm{n}=6$ per group). Values are shown as mean \pm S.E.M. and expression of genes was normalized to the housekeeping gene Cyclophilin.

S-Fig.2 Dynamic changes of lipid metabolism during cold exposure. (a) Plasma total cholesterol, (b) plasma triglyceride (TG) and (c) plasma glucose levels in RT and Cold mice. ( $\mathrm{n}=6$ per group) All data are presented as mean \pm S.E.M. $* P<0.05, * * P<$ 0.01 for the Cold compared to the control group.

\section{S-Fig.3 Morphology and gene expression changes of iBAT and WAT of mice after}

5- or 7-day cold exposure. (a) Quantitative PCR analysis of Ucp-1,Pgc-1 $\alpha$ and Ppary gene expression in BBAT and sWAT of mice after 5- or 7-day cold exposure. The data show the fold induction of the expression for the target genes in iBAT and sWAT of Cold mice. ( $\mathrm{n}=6$ for each group) Values are mean \pm S.E.M. and expression of genes was corrected for the housekeeping gene cyclophilin. $\left({ }^{*} P<0.05,{ }^{* *} P<0.01\right.$, ***P $<0.001$ ). (b) UCP-1 immunohistochemical staining of iBAT, sWAT and eWAT from mice after 5- or 7-day cold exposure (Magnification: 400×, Scale bar: $20 \mu \mathrm{m}$ ). 


\section{Figure 1}

(a)

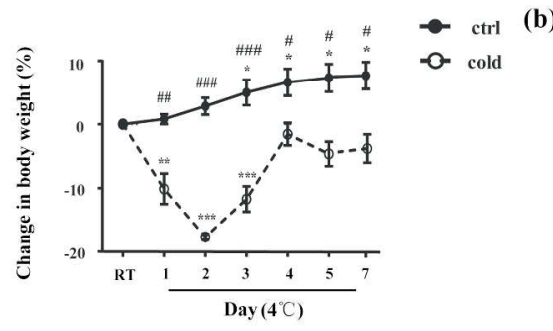

(c)

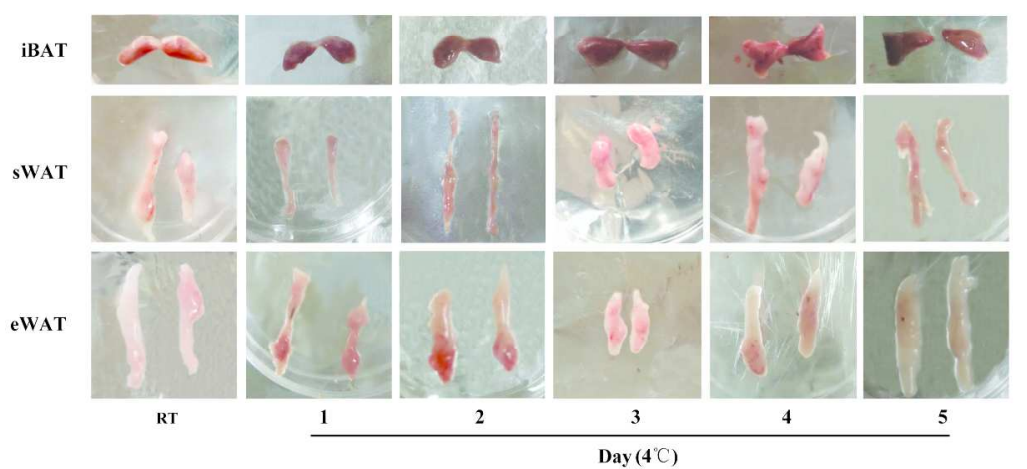

(d)
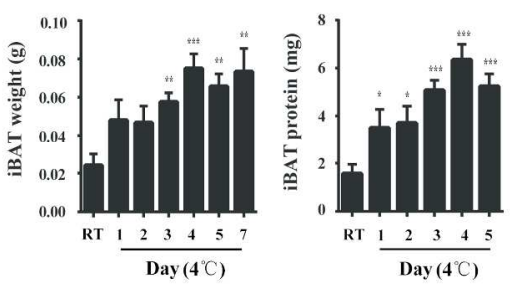

(c)

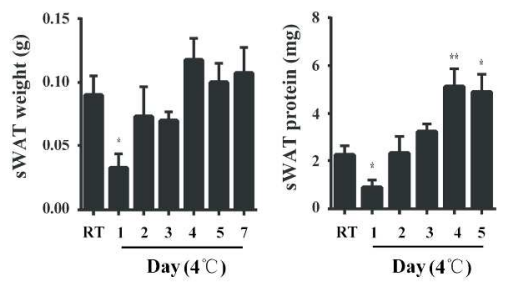

(g)
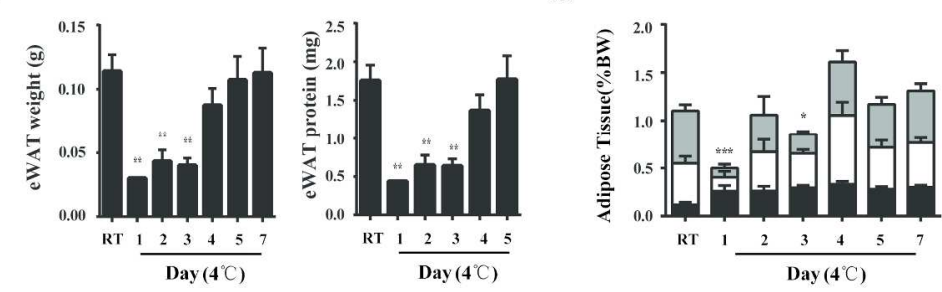

$197 \times 276 \mathrm{~mm}(300 \times 300$ DPI $)$

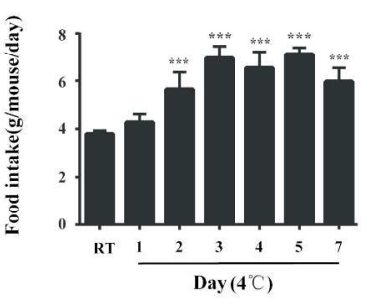




\section{Figure 2}

(a)

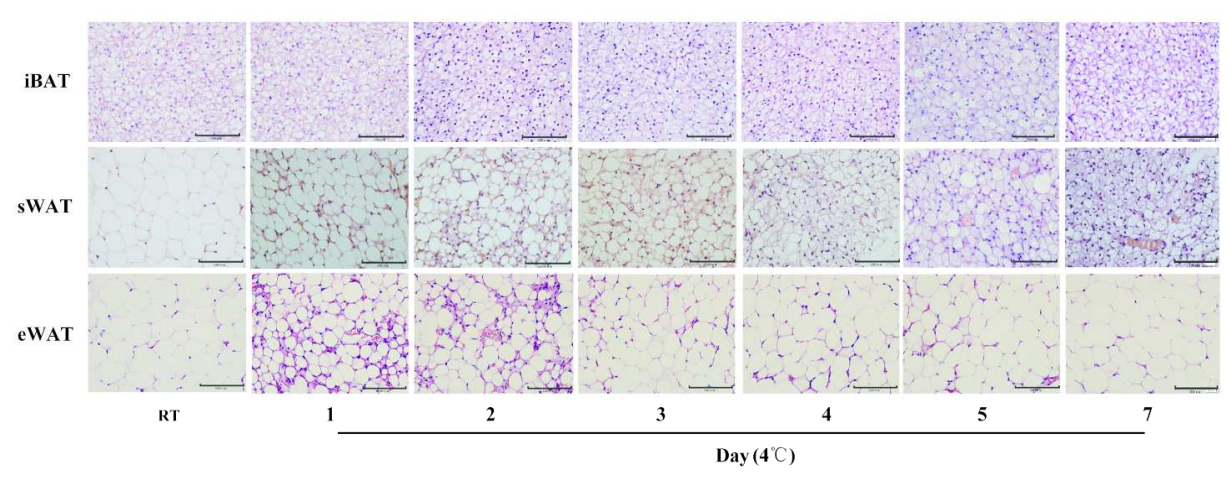

(b)
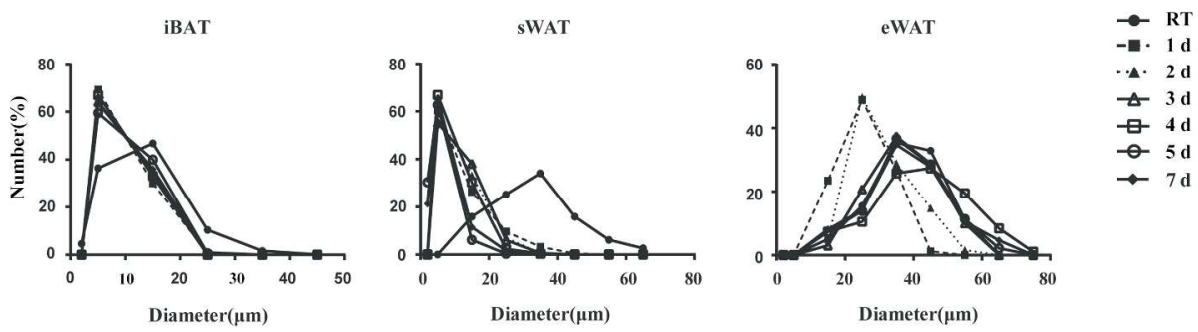

$231 \times 184 \mathrm{~mm}(300 \times 300$ DPI $)$ 
Figure 3

(a)

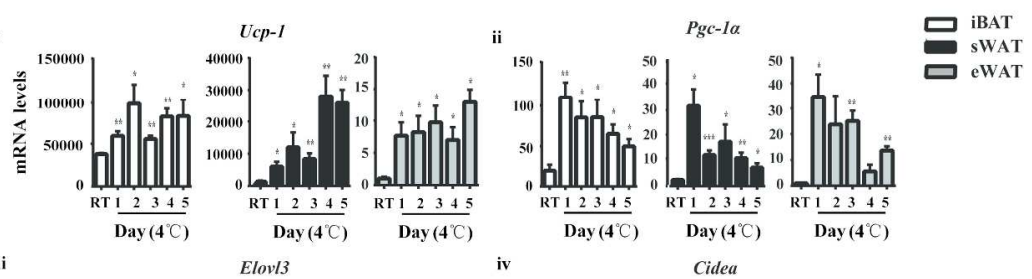

iii

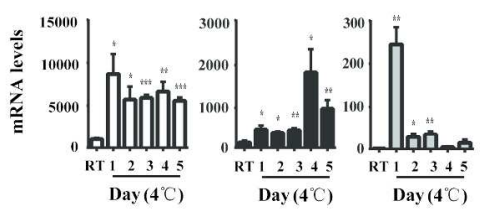

(b) ${ }_{i}$

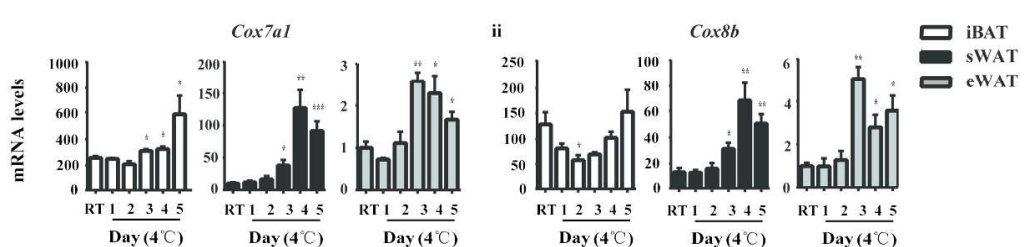

(c) ${ }_{\mathrm{i}}$
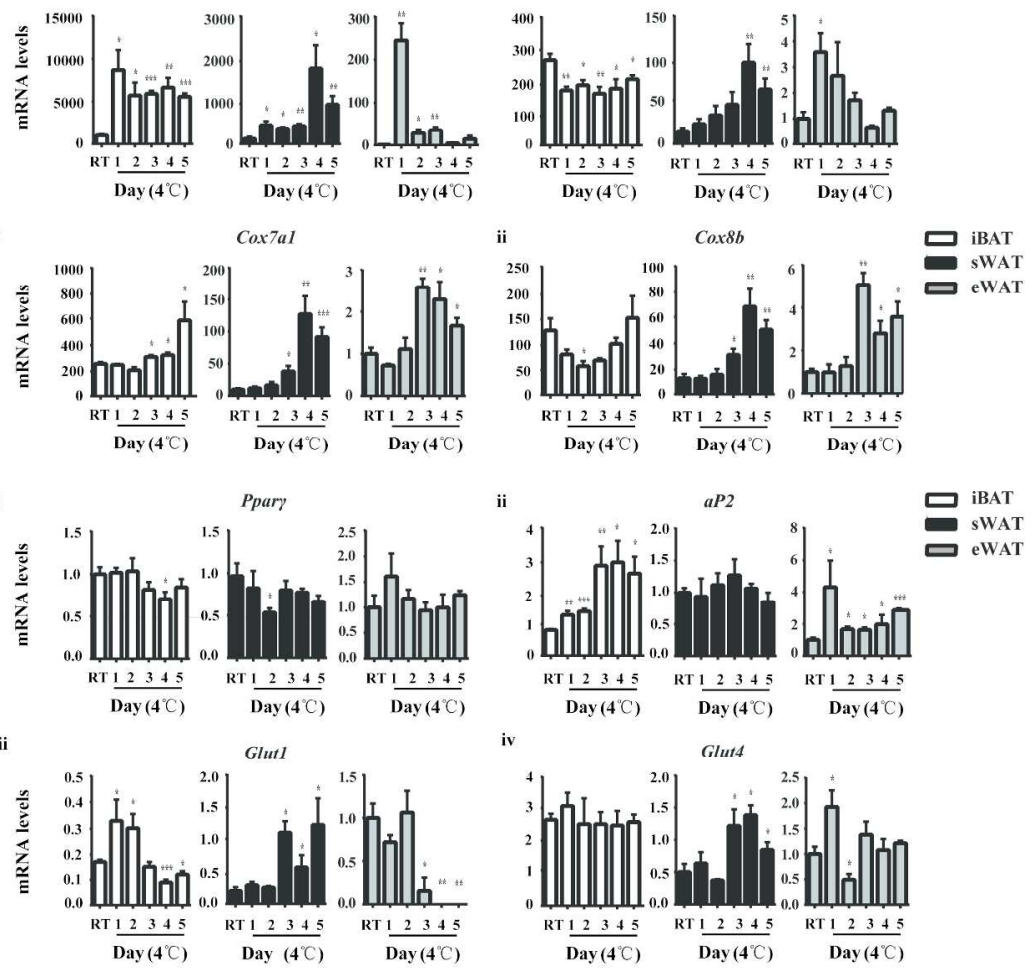

iv Gituts

(d)

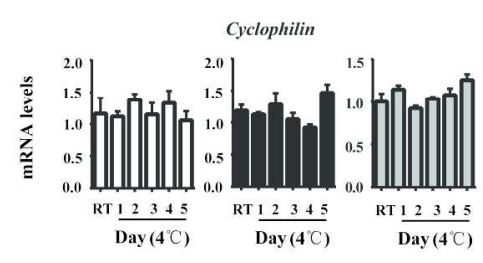

$203 \times 294 \mathrm{~mm}(300 \times 300$ DPI $)$ 


\section{Figure 4}

(a)

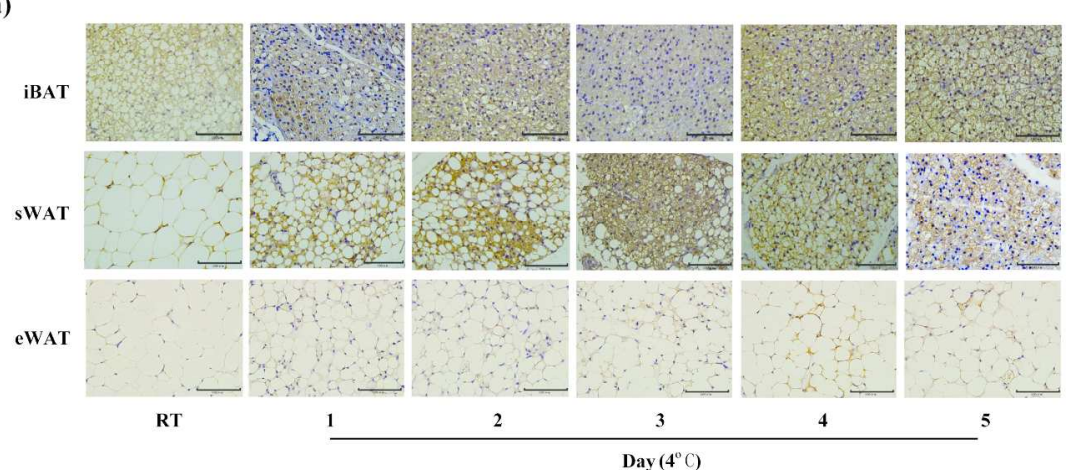

(b)

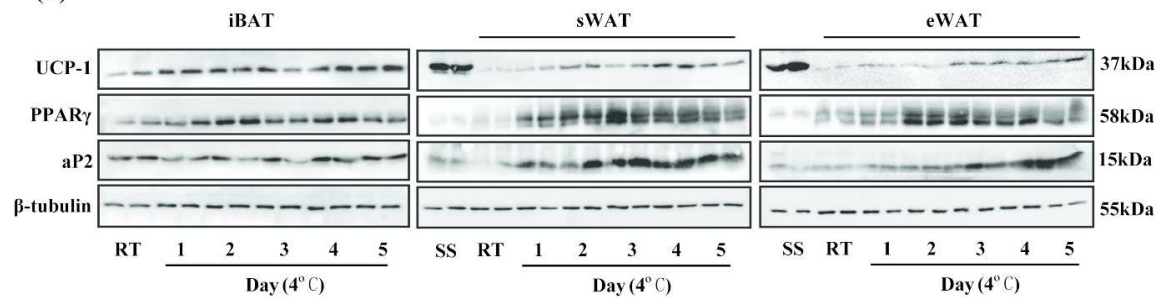

(c)
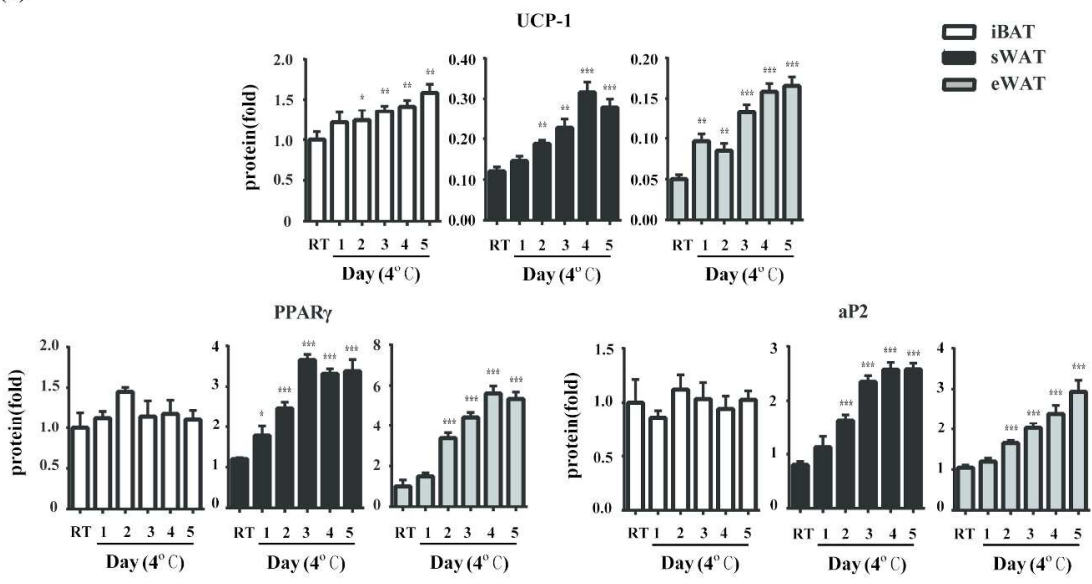

$204 \times 279 m m(300 \times 300$ DPI $)$ 


\section{Figure 5}

(a)

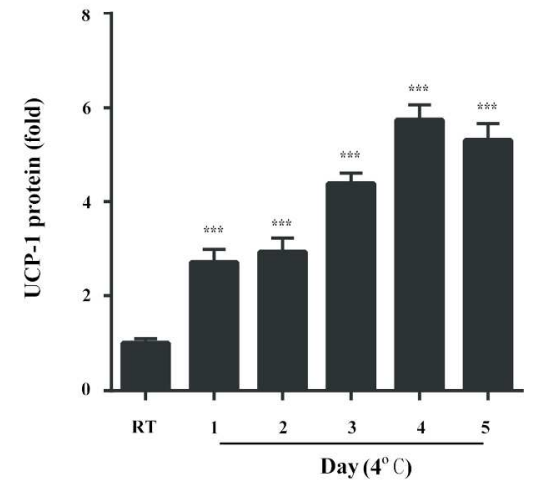

(c)

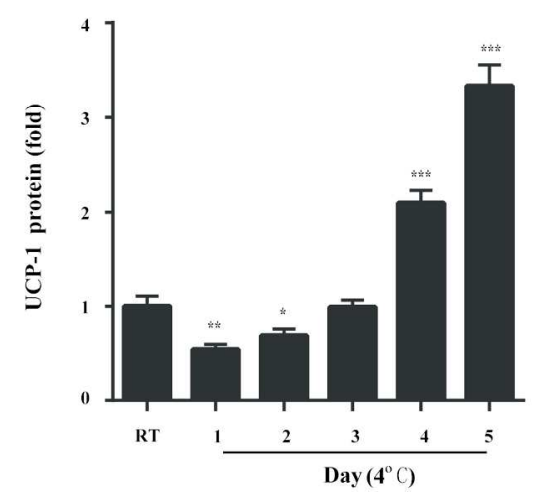

(b)

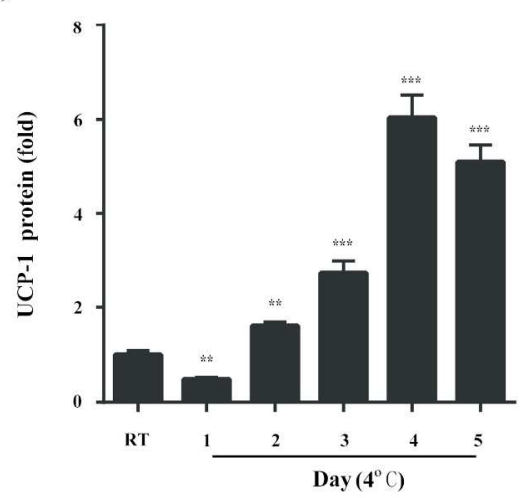

(d)

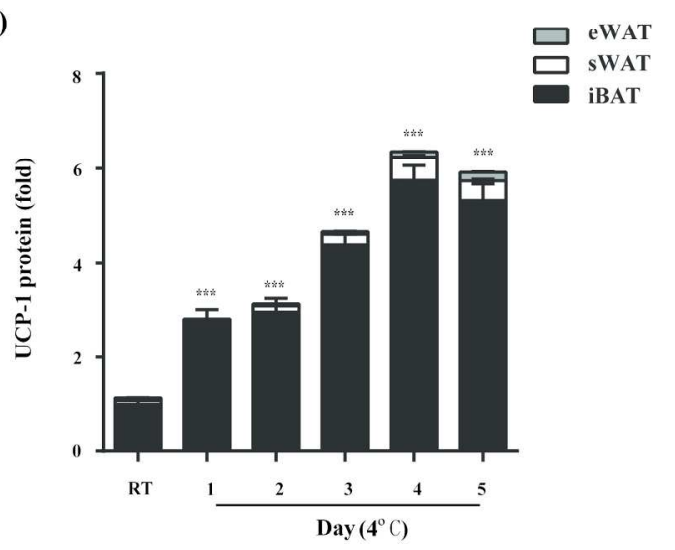

$200 \times 178 \mathrm{~mm}(300 \times 300$ DPI) 


\section{S-Figure 1}

(a)
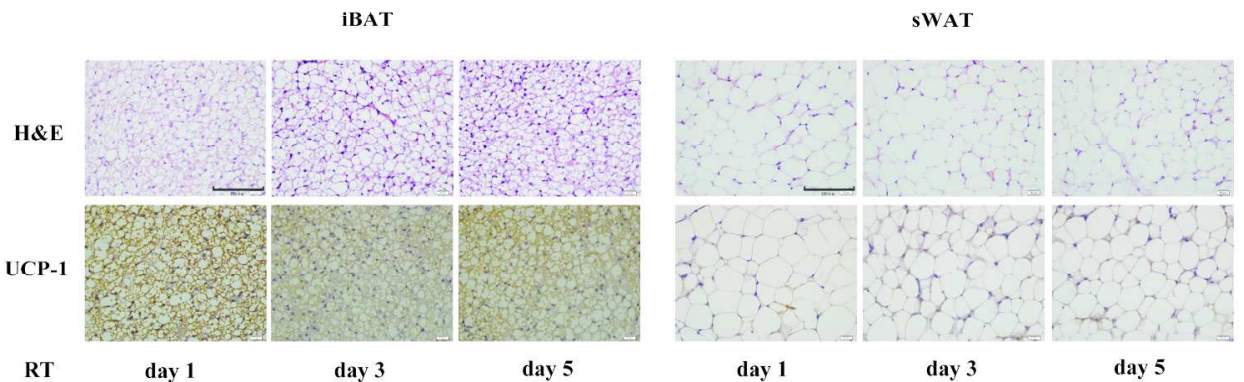

(b)

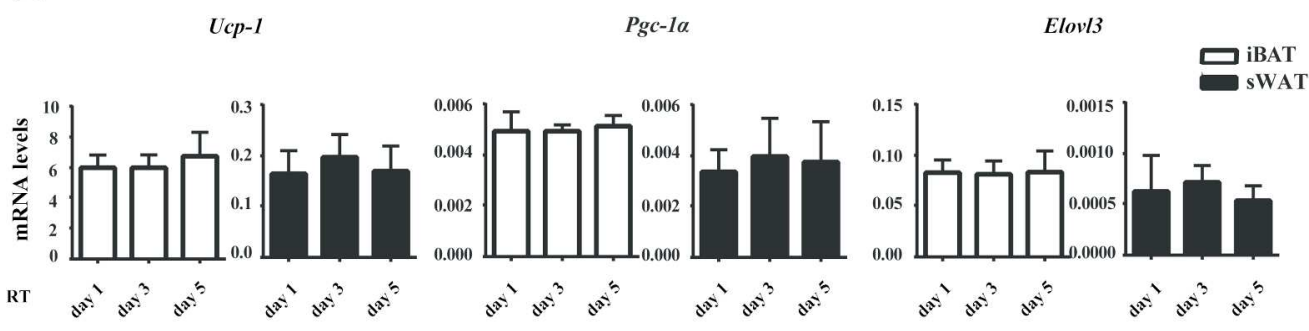

206x143mm (300 x 300 DPI) 


\section{S-Figure 2}

(a)

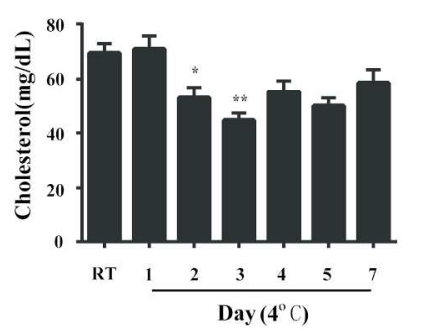

(b)

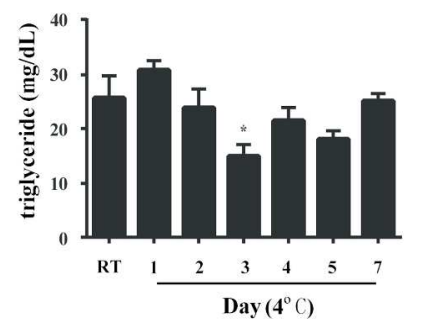

(c)

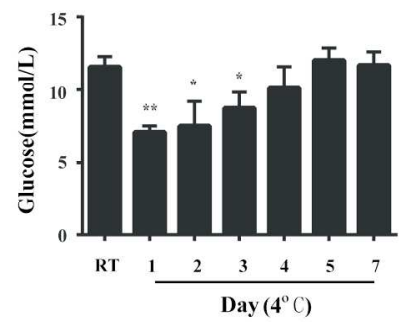

$201 \times 73 \mathrm{~mm}(300 \times 300$ DPI $)$ 


\section{S-Figure 3}

(a)
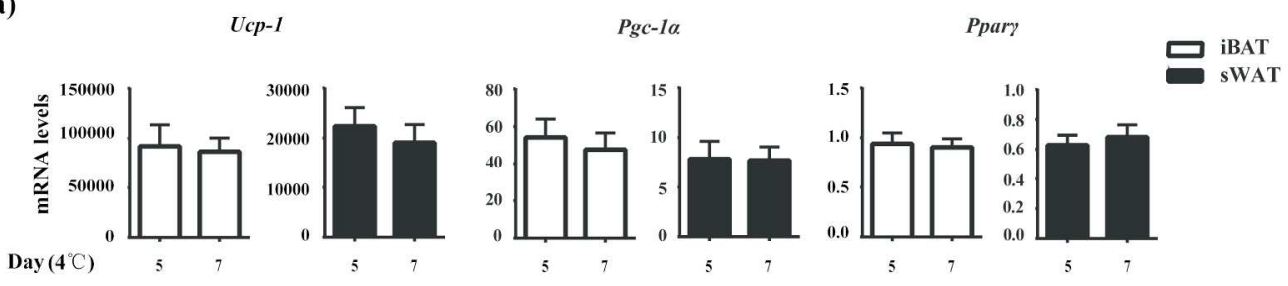

(b)
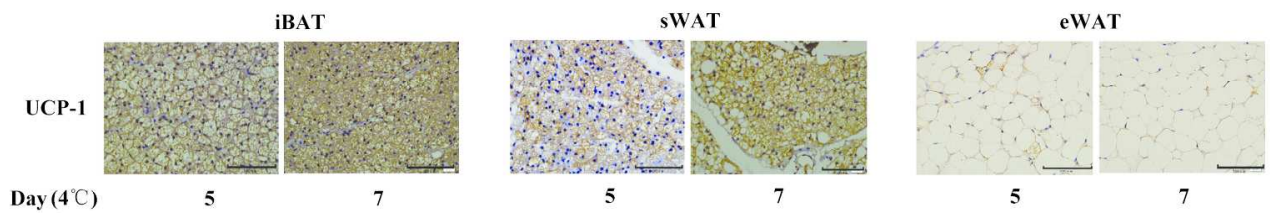

$211 \times 106 \mathrm{~mm}(300 \times 300$ DPI $)$ 